\title{
PAPER
}

\section{Dementia with Lewy bodies according to the consensus criteria in a general population aged 75 years or older}

\section{T Rahkonen, U Eloniemi-Sulkava, S Rissanen, A Vatanen, P Viramo, R Sulkava}

See Editorial Commentary, p 697-698

J Neurol Neurosurg Psychiatry 2003;74:720-724

See end of article for authors' affiliations

Correspondence to Dr Terhi Rahkonen, Division of Geriatrics, Department of Public Health and General Practice, University of Kuopio, PO Box 1627 70211 Kuopio, Finland; terhi.rahkonen@uku.fi

Received 19 August 2002 In revised form

14 January 2003

Accepted

15 January 2003
Objective: To estimate the prevalence of dementia with Lewy bodies (DLB) according to the consensus criteria in a general population aged 75 years or older.

Methods: The "Kuopio 75+ study" is a population based health survey focused on the clinical epidemiology of dementia and functional capacity among elderly subjects aged 75 years or older. On 1 January 1998, a random sample of 700 subjects was drawn from a total population born before 1 January 1923, living in the city of Kuopio, northeast Finland $(n=4518)$. The study subjects underwent a structured interview and clinical examination.

Results: 601 elderly subjects ( $86 \%$ of the random sample) were examined. A dementia disorder was diagnosed in 137-a prevalence of $22.8 \%$ (95\% confidence interval $19.4 \%$ to $26.2 \%)$. The prevalence of DLB was $5.0 \%(3.2 \%$ to $6.7 \%)$, comprising $22 \%$ of all demented subjects. Probable DLB was diagnosed in 20 subjects $(3.3 \%(1.9 \%$ to $4.8 \%))$, and possible DLB in $10(1.7 \%(0.6 \%$ to $2.7 \%))$. The prevalence of Alzheimer's disease was $10.6 \%$ (47\% of all demented subjects), of vascular dementia, $5.3 \%(23 \%)$, and of other types of dementing disorders, $1.8 \%(8 \%)$.

Conclusions: In a general population aged 75 years and older, the prevalence of a disorder fulfilling the diagnostic criteria of DLB is half that of Alzheimer's disease and the same as for vascular dementia.
$\mathrm{T}$ he presentation of dementia with Lewy bodies (DLB) is typically delirium-like, with fluctuating confusion, attentional deficits, and psychiatric symptoms, particularly visual hallucinations. Rigid-akinetic parkinsonism, intermittent loss of consciousness, and falls are other common features. The diagnostic criteria of dementia with Lewy bodies have been changing over recent years, and consensus criteria were published by McKeith et al in $1996^{1}$ (table 1). These criteria have been shown to have a relatively low sensitivity $(0.22$ to 0.83 ) but a high specificity (0.85 to 1.00$)$ with neuropathological diagnosis. ${ }^{2-7}$
Estimates of the prevalence proportion of DLB, ranging from $15 \%$ to $35 \%$ of all demented subjects, are based mainly on neuropathological series and on registers of research centres. ${ }^{8-10}$ There has been only one Western population based study of the prevalence of DLB, reporting a prevalence of $0.6 \%$

Abbreviations: $A D L$, activities of daily living; DLB, dementia with Lewy bodies; DSM, Diagnostic and statistical manual of mental disorders; IADL, instrumental activities of daily living; MMSE, mini-mental state examination

Table 1 Consensus criteria for the clinical diagnosis of probable and possible dementia with Lewy bodies (DLB) (McKeith et al, 1996')

1 The central feature required for a diagnosis of DLB is progressive cognitive decline of sufficient magnitude to interfere with normal social and occupational function. Prominent or persistent memory impairment may not necessarily occur in the early stages but is usually evident with progression. Deficits on tests of attention and of frontal-subcortical skills and visuospatial ability may be especially prominent.

2 Two of the following core features are essential for a diagnosis of probable DLB, and one is essential for possible DLB:

(a) Fluctuating cognition with pronounced variation in attention and alertness

(b) Recurrent visual hallucinations that are typically well formed and detailed

(c) Spontaneous motor features of parkinsonism

3 Features supportive of the diagnosis are:

(a) Repeated falls

(b) Syncope

(c) Transient loss of consciousness

(d) Neuroleptic sensitivity

(e) Systematic delusions

(f) Hallucinations in other modalities

4 A diagnosis of DLB is less likely in the presence of:

(a) Stroke disease, evident as focal neurological signs or on brain imaging

(b) Evidence of physical examination and investigation of any physical illness or other brain disorde sufficient to account for the clinical picture 


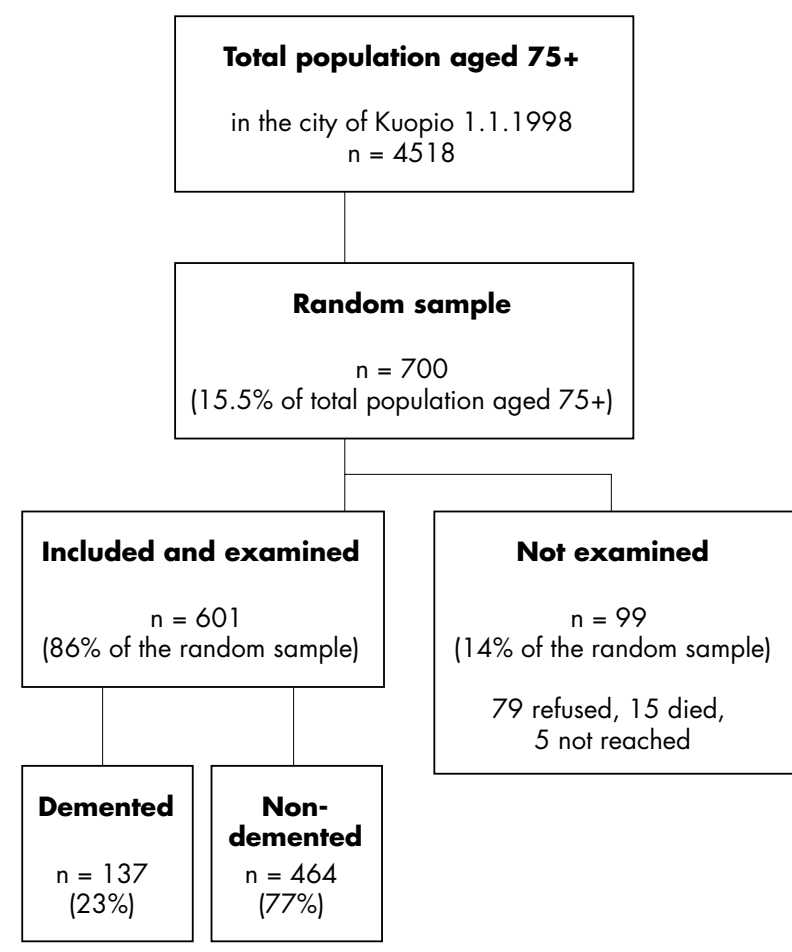

Figure 1 Flow chart of the study.

in a population aged 65 years or older, ${ }^{11}$ and two Japanese studies, which found the prevalence to be zero to $0.1 \% .^{12}{ }^{13}$

We therefore decided to study the prevalence of DLB in a health survey based on a general population aged 75 years or older in Finland.

\section{METHODS}

The Kuopio $75+$ study is a population based health survey focused on the clinical epidemiology of diseases, especially those causing dementia, and on functional capacity in elderly people aged 75 years or more. A random sample of 700 subjects was drawn from the total population of people born before 1 January 1923 and living in the city of Kuopio (population 80000 ) in eastern Finland, on l January 1998 $(\mathrm{n}=4518)$ (fig 1 and table 2$)$. In all, 601 subjects ( $86 \%$ of the random sample) were available in 1998 for a structured clinical examination and an interview by a geriatrician (AV) and a trained nurse. Ninety nine subjects could not be examined (79 refused, five could not be contacted, and 15 died before the examination).

The structured interview included items concerning sociodemographic factors, living conditions, social contacts, health behaviour, and physical health. The overall physical and neurological status was examined. The study protocol included basic laboratory tests and chest $x$ ray. Patients were also referred for further examination and imaging if warranted by their clinical condition. All medical records from the municipal health centre and from local hospitals and Kuopio University Hospital were evaluated. In addition, interviews were carried out with family members and staff in health and social care if the subject was unable to give information, needed health and social services, or lived in an institution.

A history of cognitive decline was obtained by interviewing the subject and relatives and other people who knew the subject, and from all the medical records. The behavioural and psychiatric symptoms of demented patients were obtained from the relatives or care giving personnel whenever possible, as well as from the interview and examination. The diagnosis of dementia was based on DSM-IV criteria. ${ }^{14}$ Dementia was rated as mild, moderate, or severe according to the guidelines in DSM-III-R. ${ }^{15}$ Dementia with Lewy bodies was clinically diagnosed according to the consensus criteria by McKeith et al $(1996)^{1}$ (table 1). Alzheimer's disease (all probable cases), vascular dementia, and dementia caused by other general medical conditions were diagnosed according to the DSM-IV criteria. ${ }^{14}$ All dementia diagnoses were subsequently evaluated by a neurogeriatrician (RS). The clinical diagnosis of dementia was established and the type and stage of the dementia were determined in consensus meetings, using all the data available.

Detection of the clinical features of DLB was based on a physical examination by the geriatrician and on information from the medical records, the subjects, relatives, and other people who knew the subject. Extrapyramidal symptoms were considered present when at least two of the following features were detected or reported in medical records: tremor at rest, rigidity, bradykinesia, or snuffling gait. Additionally, the presence of extrapyramidal symptoms required the exclusion of possible neuroleptic drug treatment as the cause of the symptoms.

The main criterion used to differentiate DLB and Parkinson's disease with dementia was the temporal relation of the appearance of the cognitive symptoms and extrapyramidal symptoms. If extrapyramidal symptoms were detected at least one year before the cognitive decline, the diagnosis of Parkinson's disease with dementia was made. ${ }^{16}$ The diagnosis of

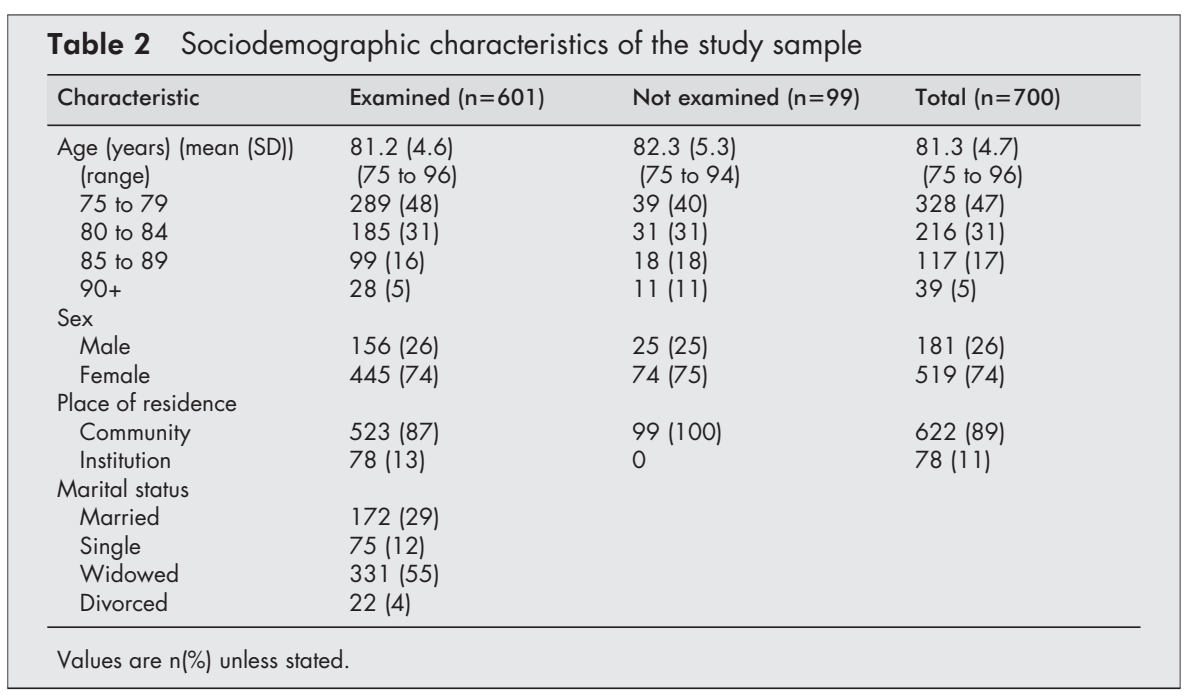


Table 3 Characteristics of subjects without dementia and with different types of dementia

\begin{tabular}{|c|c|c|c|c|c|c|}
\hline & \multirow[b]{2}{*}{ Non-demented } & \multicolumn{5}{|l|}{ Demented } \\
\hline & & $\begin{array}{l}\text { Demented, } \\
\text { total }\end{array}$ & $\begin{array}{l}\text { Alzheimer's } \\
\text { disease }\end{array}$ & $\begin{array}{l}\text { Vascular } \\
\text { dementia }\end{array}$ & $\begin{array}{l}\text { Dementia with } \\
\text { Lewy bodies }\end{array}$ & $\begin{array}{l}\text { Other types } \\
\text { of dementia }\end{array}$ \\
\hline$n(\%)$ & $464(77.2)$ & $137(22.8)$ & $64(46.7)$ & $32(23.4)$ & $30(21.9)$ & $11(8.0)$ \\
\hline Age (years) (mean (SD)) & $80.4(4.3)$ & $83.6(4.8)$ & $84.1(4.6)$ & $84.1(5.0)$ & $83.3(4.6)$ & $80.3(5.0)$ \\
\hline (range) & (75 to 96$)$ & (75 to 95$)$ & (75 to 92) & (75 to 92$)$ & (75 to 95$)$ & $(75$ to 89$)$ \\
\hline 75 to 79 & $255(55)$ & $34(25)$ & $13(20)$ & $9(28)$ & $6(20)$ & $6(55)$ \\
\hline 80 to 84 & $132(28)$ & $56(39)$ & $30(47)$ & $5(16)$ & $15(50)$ & $3(27)$ \\
\hline 85 to 89 & 65 (14) & $34(25)$ & $10(16)$ & $16(50)$ & $6(20)$ & $2(18)$ \\
\hline $90+$ & $12(3)$ & $16(11)$ & $11(17)$ & $2(6)$ & $3(10)$ & 0 \\
\hline \multicolumn{7}{|l|}{ Sex } \\
\hline Male & $127(27)$ & $29(21)$ & $12(19)$ & $9(28)$ & $4(13)$ & $4(36)$ \\
\hline Female & $337(73)$ & $108(79)$ & $52(81)$ & $23(72)$ & $26(87)$ & $7(64)$ \\
\hline \multicolumn{7}{|l|}{ Place of residence } \\
\hline Community & $446(96)$ & $77(56)$ & $37(58)$ & $16(50)$ & $19(63)$ & $5(45)$ \\
\hline Institution & $18(4)$ & $60(44)$ & 27 (42) & $16(50)$ & 11 (37) & $6(56)$ \\
\hline \multicolumn{7}{|l|}{ Length of education (years) } \\
\hline Mean (SD) & $6.9(3.5)$ & $5.6(2.8)$ & $5.8(2.6)$ & $4.5(2.2)$ & $7.0(3.9)$ & $4.4(0.9)$ \\
\hline (range) & (0.5 to 23 ) & $(1.5$ to 16$)$ & (2 to 15$)$ & (1.5 to 10$)$ & (4 to 16$)$ & $(4$ to 6$)$ \\
\hline Unknown & $34(7)$ & $79(58)$ & $36(56)$ & $19(59)$ & $18(60)$ & $6(55)$ \\
\hline \multicolumn{7}{|l|}{ Stage of dementia } \\
\hline Mild & & $48(35)$ & $23(36)$ & $11(34)$ & $9(30)$ & $5(46)$ \\
\hline Moderate & & $50(36)$ & $18(28)$ & $12(38)$ & $18(60)$ & $2(18)$ \\
\hline Severe & & $39(29)$ & $23(36)$ & $9(28)$ & $3(10)$ & $4(36)$ \\
\hline \multicolumn{7}{|c|}{ Duration of dementia (years) } \\
\hline Mean (SD) & & $4.2(3.6)$ & $4.1(3.7)$ & $4.3(3.6)$ & $4.0(3.5)$ & $4.9(3.3)$ \\
\hline (range) & & $(0$ to 19$)$ & $(0$ to 19$)$ & $(0$ to 14$)$ & $(0$ to 18$)$ & $(0$ to 11$)$ \\
\hline Less than 1 year & & $11(8)$ & $6(9)$ & $3(10)$ & $1(3)$ & $1(9)$ \\
\hline 1 to 2 years & & 45 (33) & $24(38)$ & $9(28)$ & $10(33)$ & $2(19)$ \\
\hline 3 to 6 years & & $67(49)$ & $22(34)$ & $10(31)$ & $15(50)$ & $4(36)$ \\
\hline $7+$ years & & $30(22)$ & $12(19)$ & $10(31)$ & $4(14)$ & $4(36)$ \\
\hline \multicolumn{7}{|l|}{ MMSE score } \\
\hline Mean (SD) & $26.1(3.7)$ & $12.5(7.6)$ & $12.4(7.3)$ & $11.9(8.6)$ & $14.1(6.5)$ & $10.3(9.0)$ \\
\hline (range) & $(0$ to 30$)$ & $(0$ to 25$)$ & $(0$ to 25$)$ & $(0$ to 28$)$ & $(0$ to 26$)$ & (0 to 21$)$ \\
\hline 30 to 24 & $378(82)$ & $5(4)$ & $1(1)$ & $2(6)$ & $2(7)$ & 0 \\
\hline 23 to 18 & 76 (16) & $40(29)$ & 21 (33) & $7(22)$ & $8(27)$ & $4(36)$ \\
\hline 17 to 12 & $5(1)$ & $44(32)$ & $17(27)$ & $2(36)$ & $13(43)$ & $2(18)$ \\
\hline 11 to 0 & 5 (1) & $48(35)$ & 25 (39) & $11(34)$ & $7(23)$ & $5(46)$ \\
\hline \multicolumn{7}{|l|}{ Barthel index score } \\
\hline Mean (SD) & $94.1(13.2)$ & $58.2(34.5)$ & $63.8(35.0)$ & $50.1(36.6)$ & $60.9(28.2)$ & $42.7(36.6)$ \\
\hline (range) & (0 to 100) & (0 to 100$)$ & (0 to 100$)$ & (0 to 100$)$ & (0 to 100$)$ & (0 to 100$)$ \\
\hline Missing* & 9 & 9 & 5 & 2 & 2 & 0 \\
\hline \multicolumn{7}{|l|}{ IADL score } \\
\hline Mean (SD) & $6.8(1.6)$ & $3.6(2.5)$ & $3.9(2.4)$ & $3.1(82.1)$ & $3.3(2.8)$ & $4.3(2.3)$ \\
\hline (range) & $(0$ to 8$)$ & $(0$ to 8$)$ & $(0$ to 8$)$ & $(0$ to 6$)$ & $(0$ to 8$)$ & (3 to 7$)$ \\
\hline Missing* & 63 & 80 & 34 & 23 & 15 & 8 \\
\hline
\end{tabular}

depression was made according to the DSM-IV criteria (proxies were interviewed in cases of dementia). ${ }^{14}$

The activities and instrumental activities of daily living were assessed with the Barthel index of $\mathrm{ADL}^{17}$ and the IADL scale, ${ }^{18}$ respectively. The mini-mental state examination test $(\text { MMSE })^{19}$ was used to screen cognitive capacity.

\section{Ethical issues}

Written informed consent for the study was obtained from subjects or their relatives. The ethics committee of the Kuopio University Hospital approved the study.

\section{Statistical analyses}

Statistical analyses were made with SPSS for Windows 9.0. Student's $t$ test for continuous variables and $\chi^{2}$ test for nominal variables were used when comparing groups. The 95\% confidence intervals (CI) of prevalence rates were calculated.

\section{RESULTS}

A dementia disorder was diagnosed in 137 subjects, giving a prevalence of $22.8 \%$ (95\% CI $19.4 \%$ to $26.2 \%$ ) among the persons aged 75 years or older (table 3). Dementia with Lewy bodies was found in 30 subjects, with a prevalence of $5.0 \%$
(3.2\% to $6.7 \%$ ). Probable DLB was diagnosed in 20 subjects $(3.3 \%(1.9 \%$ to $4.8 \%))$ and possible DLB in 10 subjects $(1.7 \%$ $(0.6 \%$ to $2.7 \%)$ ). Alzheimer's disease was diagnosed in 64 subjects, with a prevalence of $10.6 \%(8.2 \%$ to $13.1 \%)$. Vascular dementia was diagnosed in 32 subjects, with a prevalence of $5.3 \%(3.5 \%$ to $7.1 \%)$.

Among the demented subjects, dementia with Lewy bodies comprised $21.9 \%(15.0 \%$ to $28.8 \%)$ of cases, Alzheimer's disease, $46.7 \%(38.4 \%$ to $55.1 \%)$, and vascular dementia, $23.4 \%$ ( $16.3 \%$ to $30.4 \%$ ). Table 4 shows the clinical diagnostic features of subjects with DLB according to the consensus criteria of McKeith et al.

Other dementing disorders $(n=11,8 \%$ of the demented subjects) included two cases of normal pressure hydrocephalus, two cases of Parkinson's disease with dementia, two cases of alcohol related dementia, one case of meningioma, two cases with schizophrenia with dementia, one case of frontotemporal dementia, and one case with severe dementia of unknown cause.

\section{DISCUSSION}

A random sample of all the elderly citizens aged 75 years or older from the city of Kuopio on 1 January 1998 was used in 


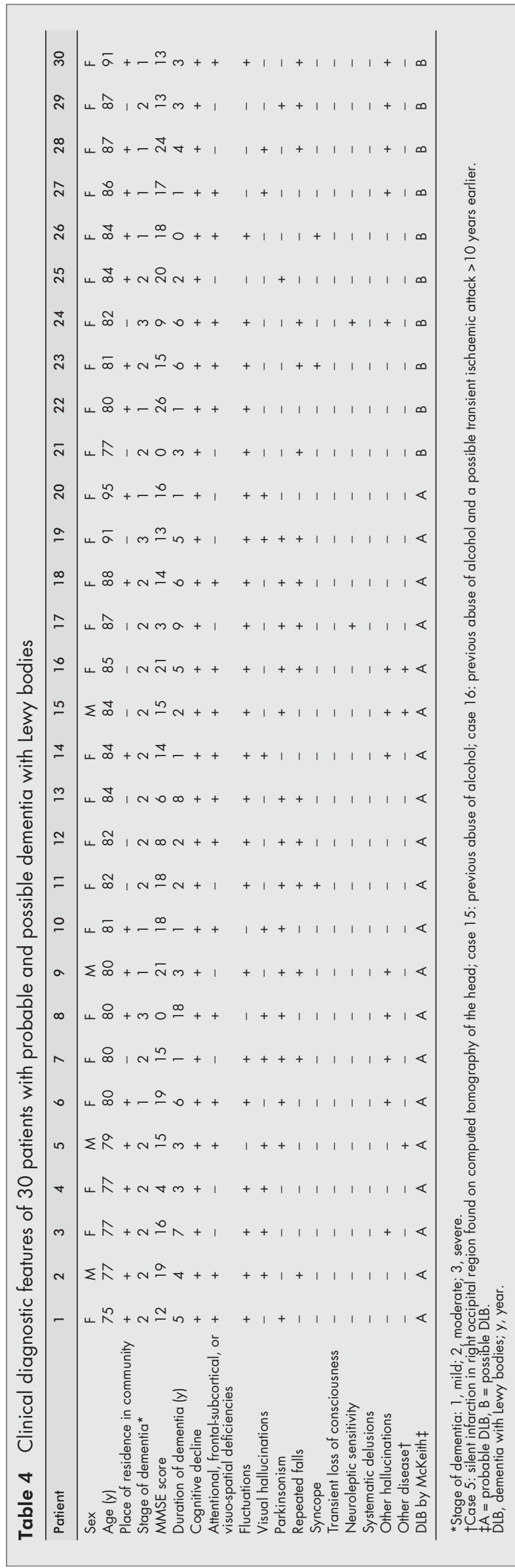

this study. In all, 601 subjects ( $86 \%$ of the random sample) were examined. Those who did not participate in the study did not differ from participants in their sex distribution, but they were a little older than the participants. All the nonparticipants lived in the community.

The prevalence of dementia of $23 \%$ in a population aged 75 years or older is slightly higher than the values of $4.2-15.6 \%$ found in previous population based studies in Europe and the USA. $^{20-28} \mathrm{~A}$ possible reason for the higher prevalence in our study might be the bias caused by the non-participants living in the community, who were less likely to be demented than patients living in institutions. However, the prevalence of dementia is $19.6 \%$ when calculated for the whole population sample drawn in our study.

The prevalence of DLB was 5.0\% (95\% CI, 3.2\% to 6.7\%), comprising $22 \%$ of the demented subjects. The prevalence of probable DLB was 3.3\% (15\% of all demented subjects) and of possible DLB, $1.7 \%$ (7\% of all demented subjects). In the recent studies, the prevalences of DLB have been much lower. ${ }^{11-13}$ However, the age of the population in our study was older.

The clinical diagnosis of DLB was based on the clinical examination (lasting one to two hours per patient), on the information from the patients' proxies, and from all the medical records available. The reliable identification of fluctuating cognitive function and confusion, one of the key diagnostic features in DLB, was the major source of diagnostic difficulty in our study. DLB is often underdiagnosed, especially in subjects living alone. The use of neuroleptic drugs (low doses of neuroleptics were used regularly or occasionally by 18 patients with DLB) may have had an effect on the severity of extrapyramidal symptoms, though spontaneous symptoms of parkinsonism were also reported previously in these cases. In the prospective study by McKeith et al, ${ }^{7}$ the major difficulties were in the detection of visual hallucinations and parkinsonism. However, when the consensus criteria are employed in the diagnosis of DLB, good diagnostic specificity and inter-rater reliability can be achieved. ${ }^{27}$ The criteria have been reported to be less useful for identifying cases in clinical settings (relatively low sensitivity), although when the diagnosis is made it is likely to be correct. ${ }^{2930}$

In our study, more subjects with DLB lived in the community, were at a less severe stage, and had shorter duration of the dementing disorder than subjects with other types of dementia. One possible explanation for these differences may be the difficulties in differentiating the subtypes of dementia in the most severe cases. At the severe stage of dementia, the clinical features of Alzheimer's disease are remarkably similar to those of DLB. Subjects with DLB might also die earlier in the course of dementia than patients with other dementias.

In our study we described the clinical features of the DLB patients examined. However, mixed pathologies in DLB and Alzheimer's disease are common according to published reports. $^{41031}$ The proportion of subjects with clinically diagnosed DLB who were actually suffering from neuropathologically pure DLB in our study remains unclear.

\section{Conclusions}

The prevalence of the disorder fulfilling the clinical diagnostic criteria of DLB was high, at 5\%, in a general population aged 75 years or older, and $22 \%$ among all patients with dementia. As we lack a prospective follow up of the subjects, we may assume that our figures represent an underestimate of the true frequency of DLB symptoms.

\section{ACKNOWLEDGEMENTS}

We thank Mrs Leena Pelkonen RN for performing the interviews with the study subjects, and Mrs Päivi Heikura for maintaining the database of the Kuopio $75+$ study. This study was supported by the 
Alzheimer Foundation of Finland, the Emil Aaltonen Foundation, and the Nordic Red Feather of the Lions.

\section{Authors' affiliations}

T Rahkonen, U Eloniemi-Sulkava, A Vatanen, P Viramo, R Sulkava, Division of Geriatrics, Department of Public Health and General Practice, University of Kuopio, Finland

S Rissanen, Academy of Finland, Department of Health Policy and Management, University of Kuopio

Competing interests: none declared

\section{REFERENCES}

1 McKeith IG, Galasko D, Kosaka K, et al. Consensus guidelines for the clinical and pathologic diagnosis of dementia with Lewy bodies (DLB): report of the consortium on DLB international workshop. Neurology 1996:47: $1113-24$

2 Mega MS, Masterman DL, Benson DF, et al. Dementia with Lewy bodies: reliability and validity of clinical and pathologic criteria. Neurology 1996:47: 1403-9.

3 Litvan I, Maclntyre A, Goetz CG, et al. Accuracy of the clinica diagnoses of Lewy body disease, Parkinson disease, and dementia with Lewy bodies. A clinicopathologic study. Arch Neurol 1998;55:969-78.

4 Holmes C, Cairns N, Lantos P, et al. Validity of current clinical criteria for Alzheimer's disease, vascular dementia and dementia with Lewy bodies. Br J Psychiatry 1999;174:45-51.

5 Verghese J, Crystal HA, Dickson DW, et al. Validity of clinical criteria for the diagnosis of dementia with Lewy bodies. Neurology 1999:53:1974-82.

6 Hohl U, Tiraboschi P, Hansen LA, et al. Diagnostic accuracy of dementia with Lewy bodies. Arch Neurol 2000;57:347-51.

7 McKeith IG, Ballard CG, Perry RH, et al. Prospective validation of Consensus criteria for the diagnosis of dementia of dementia with Lewy bodies. Neurology 2000;54:1050-8.

8 Hansen L, Salmon D, Galasko D, et al. the Lewy body variant of Alzheimer's disease: a clinical and pathological entity. Neurology 1990;40: 1-8.

9 Perry RH, Irving D, Blessed G, et al. Clinically and pathologically distinct form of dementia in the elderly. Lancet 1989;i: 116.

10 Perry RH, Irving D, Blessed G, et al. Senile dementia of Lewy body type: a clinically and neuropathologically distinct form of Lewy body dementia in the elderly. J Neurol Sci 1990;95:119-39.

11 Stevens T, Livingston G, Kitchen G, et al. Islington study of dementia subtypes in the community. BrJ Psychiatry 2002;180:270-6.

12 Yamada T, Hattori H, Miura A, et al. Prevalence of Alzheimer's disease, vascular dementia and dementia with Lewy bodies in a Japanese population. Psychiatry Clin Neurosci 2001;55:21-5

13 Yamada T, Kadekaru H, Matsumoto S, et al. Prevalence of dementia in the older Japanese-Brazilian population. Psychiatry Clin Neurosci 2002;56:71-5
14 American Psychiatric Association. Diagnostic and statistical manual of mental disorders, 4th ed. Washington, DC: American Psychiatric Association, 1994.

15 American Psychiatric Association. Diagnostic and statistical manual of mental disorders, 3rd ed, revised. Washington, DC: American Psychiatric Association, 1987.

16 Sulkava R. Differential diagnosis between early Parkinson's disease and dementia with Lewy bodies. In: Gordin A, ed. Parkinson's disease. Advances in neurology. Philadelphia: Lippincott Williams and Wilkins, 2003:41 1-13.

17 Mahoney FI, Barthel DW. Functional evaluation: the Barthel Index. Md State Med J 1965;14:61-5.

18 Lawton MP, Brody EM. Assessment of older people; self-maintaining and instrumental activities of daily living. Gerontologist 1996;9:179-86.

19 Folstein MF, Folstein SE, McHugh PR. "Mini-mental state." A practical method for grading the cognitive state of patients for the clinician. $J$ Psychiatr Res 1975;12:189-98.

20 Sulkava R, Wikström J, Aromaa A, et al. Prevalence of severe dementia in Finland. Neurology 1985;35:1025-9.

21 Rocca WA, Bonaiuto S, Lippi A, et al. Prevalence of clinically diagnosed Alzheimer's disease and other dementing disorders: a door-to-door survey in Appignano, Macerata Province, Italy. Neurology 1990:40:626-31.

22 Fratiglioni L, Grut $M$, Forsel $Y$, et al. Prevalence of Alzheimer's disease and other dementias in an elderly urban population: relationship with age, sex, and education. Neurology 1991;41:1886-92.

23 Copeland JR, Davidson IA, Dewey ME, et al. Alzheimer's disease, other dementias, depression and pseudodementia: prevalence, incidence and three-year outcome in Liverpool. Br J Psychiatry 1992;161:230-9.

24 Juva K, Sulkava R, Erkinjuntti T, et al. Prevalence of dementia in the city of Helsinki. Acta Neurol Scand 1993;87:106-10.

25 Koivisto K. Population-based dementia screening program in the city of Kuopio, eastern Finland. Kuopio: Department of Neurology, University of Kuopio, 1995. [Thesis.]

26 Lobo A, Saz P, Marcos G, et al. The prevalence of dementia and depression in the elderly community in a southern European population. The Zaragoza study. Arch Gen Psychiatry 1995;52:498-506.

27 Erkinjuntti T, Østbye T, Steenhuis R, et al. The effect of differen diagnostic criteria on the prevalence of dementia. N Engl J Med 1997;337: 1667-74.

28 Fillenbaum GG, Heyman A, Huber MS, et al. The prevalence and 3 -year incidence of dementia in older black and white community residents. J Clin Epidemiol 1998;51:587-95.

29 Lopez OL, Litvan I, Catt KE, et al. Accuracy of four clinical diagnostic criteria for the diagnosis of neurodegenerative dementias. Neurology 1999;53:1292-9.

30 McKeith IG, O'Brien JT, Ballard C. Diagnosing dementia with Lewy bodies. Lancet 1999;356:1227-8

31 Lippa CF, Smith TW, Swearer JM. Alzheimer's disease and Lewy body disease: a comparative clinicopathological study. Ann Neurol 1994;35:81-8. 